\title{
China Set Sights on Hosting World Cup: A Case Study of the 2014 FIFA World Cup in Brazil
}

\author{
Shengyu $\mathrm{Gu}^{1}$, Ying-Wei $\mathrm{Wu}^{2}$ \\ ${ }^{1}$ National Kaohsiung University of Hospitality and Tourism \\ ${ }^{2}$ National Kaohsiung University of Hospitality and Tourism
}

\begin{abstract}
The glamour of hosting a major sporting tourism activity like the FIFA World Cup is thrilling. However, the success of such an event requires prior extensive planning and preparation, including determining the feasibility of the event. The objective of this study was to ascertain the tourism impacts and significance of the Brazil 2014 World Cup and its implications in discussing China's feasibility of hosting a World Cup in the future. This study adopted a case study qualitative research method to analyse the dynamics that surrounded the preparation and the tourism impacts of the Brazil 2014 FIFA World Cup to evaluate the feasibility of China hosting such an event. The data collection and analysis approach was purely through a literature review of secondary sources, including print media, online reports, and pictures related to the impact of the FIFA World Cup to Brazil and its vibrant tourism sector. The study determined that as much as China does not match the rich football history that Brazil identifies with, China has state-of-the-art sporting facilities that enhance its capability of hosting a World Cup event. The country has been able to host many other global events, such as the 2008 Olympics in Beijing. Furthermore, over time, the country's football levels have notably improved due to significant investments by Chinese investors in football, a strategy that has led to the attraction of global talents. The country has experienced massive investments that have led to the development of modern training facilities as well as stadiums, and therefore the country is able to host a massive global sporting event like the FIFA World Cup.
\end{abstract}

Keywords: FIFA World Cup, Sports tourism, Feasibility, Hosting, Sporting facilities

\section{Introduction}

Tourism in most parts of the world varies extensively because of the varying tourist attracting aspects in these different parts of the world. In Europe for example, tourism is more rampant over the summer where individuals can travel more freely without being restricted by the harsh climatic conditions witnessed during winter. In this case study tourism as a dependent variable is brought into direct correlation with other variables and an explanation given on the significance of each of these variables in a case study country. In this descriptive research, there are three key aspects that researcher seeks to answer. These are what, how, and why the sport has been able to influence tourist activities in a case study country and what impact did the sporting activity have on the host nation. In this descriptive research, a clear outline of the methods used to collect and evaluate data on the case study area is listed. In the research that was carried out, different strategies were put in place to ensure that adequate and reliable information was collected to aid analysis. The study is based on a particular case country, in relation to another, which wishes to host a particular sporting activity in the near future (Simon \& Stefan, 2009). A feasibility report was later generated where China's ability to host a major sporting event in the 
future was evaluated in relation to the FIFA World Cup hosted by Brazil in 2014 and the significance of this event to Brazil's Tourism sector (Richard, 2012).

\section{Literature Review}

Brazil is a major global destination for tourists. The country has vast tourist attraction sites, ranging from the thick rainforests of the Amazonia to the extensive beaches of Rio de Janeiro. The country, therefore, boasts quite significant revenue generated from annual visits made by tourists, both on the local and on the international scenes. Brazil, aside from being a tourist destination, is a football powerhouse; it has won the FIFA World Cup more than any country. Football in the country is said to have heavily changed from not only being a professional sport but also being a key attraction for tourists (Amelia, 2010). A blend of Brazilian Samba dance and street football is an example of the football activities that markets Brazil's tourist attractions as well as developing its football.

In relation to the research's topic, it is important to know the history of a particular country as well as the achievements it has witnessed over time (Jaci, 2011). Similarly, we ought to have adequate knowledge of China and its football structure; from this information, we will be able to give an arguably perfect comparison between Chinese and Brazilian football. From these, we can give an elaborate overview of what needs to be done to boost global football standards, aside from countries bettering their facilities and standards, in order to win bids for hosting international football events. The main questions are: is China able to host a FIFA World Cup? Can this boost China's football tourism? How does China's football tourism compare with that of Brazil? There are key aspects that we will always put in consideration when comparing a country with the standard requirements of hosting a global competition; these are the political will and support to the competition, facilities for use in the event, and the general significance of the event in the global domain (Lu, 2012).

Aside from direct implications of global sporting events to a host country, there are other side requirements that will dictate a country's feasibility to host a major global event. Some of these requirements include security provisions, housing facilities, access to food, mobility, and above all a suitable environment for the game to be held. The research methods need to cater to this wide scope of the research topic. Furthermore, clarity of facts is critical; it is from the statement of facts that we can be able to ascertain China's ability to host a FIFA World Cup, as well as its ability support football tourism as Brazil has.

\section{Methodology}

\subsection{Information Collection and Feasibility Analysis}

The research method employed in this study was that of the case study methodology, which in essence is a qualitative approach. A case study research method reviews a real-life occurrence through the use of evidence derived from multiple sources (Yin, 2009). Information is the facts that are stated regarding the attributes that a particular aspect portrays. A good understanding of a subject is reached by using strategies that necessitate accurate fact-finding. A researcher is therefore required to use a good data collection strategy that will guarantee the research is an accurate analysis and conclusions are based on substantial facts. In this case, the research is qualitative; we, therefore, need to choose a reliable qualitative method of collecting, analysing, and presenting information that relates to a particular topic.

A quality structure is inadequate in subjective research. For example, beyond the fundamental customs, there are no tried measurements that can be used to think about one qualitative review in relation to another. While exploration of research is basic to enhancing the nature of what we do, the subjective showcasing research of the world has been glaringly truant from the investigative scene (Tang, 2004). To better comprehend the impact of factors there is a need to undertake a centre gathering examination. The examination may need to take into account factors such as the consideration of expert members, the nearness of onlookers, and mediator impacts. However, a lot of this work is done outside the expert field, and extensive discourses on these and comparable 
issues are, in every practical sense, nonexistent (William, 2015).

Research methods are situational, determined by the situation in which particular research is to be carried out and what objectives the research aims to achieve. The major determinants of which research method to choose from include dynamics of a research, its environment, and intentions (Davis \& Clark, 1987). In this case, a case study-based qualitative research method was used to obtain and analyse secondary information on the impact of the 2014 FIFA World Cup to Brazil and its tourism, as well as China's objective to host a world cup event in the future. A quality research is a research seeking to explore the validity of stated opinions. Qualitative research is used to provide an elaborate definition and understanding of motivations of occurrences, existent opinions, and underlying reasons.

Qualitative research methods avail insights on critical issues, develop research questions, and give and brief hypotheses of the research. In this case study, qualitative research methods are used to uncover the truth about the impact of football as a sport and as a recreation to Brazil's tourism sector. Furthermore, qualitative research method collects information using varied structural and semi-structural techniques (Mehta \& Sivadas, 1995). The key strategies, which this method uses, include a comprehensive target data-source selection and observations. Attributes of a good report are owed to a good method of collecting information; the credibility of information is, therefore, the core aspect that every research has to consider.

Information regarding the impact of the 2014 FIFA World Cup to Brazil's tourism was collected through secondary data collection and analysis of archival data (Alex, 2002). The data sources were published materials with information about past FIFA major sporting activities. These secondary sources included print media, online reports, and pictures: all of these were related to the impact of the FIFA world cup to Brazil and its vibrant tourism sector. The information collected was recorded awaiting analysis (O'Neill, 2014).

China in the recent past has emerged to be a global economic powerhouse. This is evident by the rate at which its industries have grown, as well as the significant skyrocketing Gross Domestic Product of the country. Chinese authorities over time have created strategies aimed at bettering all its facilities, irrespective of the costs it has to incur to achieve these ambitious objectives. China, in regard to sporting activities, can be said to be at its developmental stage. This is to say that, the country's sporting participants have not yet achieved much in sporting activities, and even less so in football. In relation to the case study, a qualitative research was carried out to determine the level of Chinese football and its significance in boosting football tourism.

In Brazil, football is a way of life. Most of the citizens are involved in or play football. Similar to data collection done on Brazilian football culture, Chinese culture on football was evaluated. The method used to collect information was that of secondary data collection. The data was collected with the aim of drawing an understanding to determine the general impact of football to the Chinese society, the achievements that Chinese Football Association, and its ability to host a world cup event in the future (Dave, 1994). The target data sources from which information was drawn were based on their discussion with the sport as well as associated with developing the sport in China.

\section{Results and Discussions}

Sporting events always have a substantial impact on a host country. The effects range from social to economic impacts on the host nation. The 2014 FIFA World Cup had many impacts to the Brazilian society, most notably on its economy. The subject of the topic is to ascertain the impact in which the event had to Brazil's, it is also very important to outline other impacts of the event on Brazil. The impacts of the 2014 World Cup in Brazil influenced Brazil's tourism, its economy, the social life of World Cup matches' host cities, and the social life as a whole.

\subsection{Impact of Tourism and Economy: 2014 FIFA World Cup in Brazil}

The number of tourists who visit tourists' attraction sites within a particular country always determines the 
tourism returns of that particular country. The number of these sites also determines it, as well as how attractive these sites are in order to keep tourists yearning to frequent them. The World Cup led to an influx of foreign citizens in Brazil who majorly came to support their respective countries in the event. After the event's completion, most of them did not just go back home, they had to tour some major tourist attraction sites within the country. Tourist activities and the revenues that result therefore increased earning sizable revenue generations.

Any tourist travelling to Brazil will always want to have a glimpse of the country's football culture. The World Cup not only motivated potential footballers, but also motivated further growth of football facilities that would be used by both professional footballers. Football fans representing their countries in the World Cup, as well as respective teams, will always rent hotel rooms and go to recreational facilities. The Brazilian economy was able to make considerable revenue from hospitality services and products they offered to the existent large number of foreign and local football supporters. The event had some significant impact on the security of the cities that hosted the competitions (Richard, 2014). Brazil is known to have fierce gangs in some of its cities, such as Favelas. During the World Cup, security was upped and there was a higher degree of safety within Favelas.

For global events to be hosted, adequate capital is required. In Brazil, a significantly huge amount of capital was spent in improving football stadiums, as well as other facilities and services that the event would possibly require (Richard, 2014). The money to fund the competition was so huge that the country's economy witnessed adverse effects. It is understood that there is a huge disparity between the rich and the poor in Brazil. Much of the taxpayer's money was spent on the event instead of focusing on development projects that would reduce poverty and create more jobs for the unemployed.

\subsection{Feasibility of China Hosting a World Cup}

Feasibility analysis is the process of analysing the capability or probability of a particular project or objective to be practically achieved. A feasibility test is done before analysis is made. The analysis is always made based on a standard project that has already been done, and comparisons are made assigning each project marks regarding objective achievability. In this case, the feasibility is done based on the capital, facilities, and equipment required to host the World Cup relative to the facilities that have been used in past successful World Cup events (Edward, 2014).

China, as stated earlier, is a global economic powerhouse, which has objected to venturing in diverse activities for them to meet their long-term objectives. The World Cup bids to host the event for 2018 and 2022 have already been won by both Russia and Qatar, respectively. In the recent past, the football governing body FIFA has increased the number of teams that will participate in the 2026 World Cup from 32 to 48 teams. Because of these additional teams, there comes a challenge for the host nation to have the capacity of the hosting the mega event. The event will be bigger in that, the facilities that are to be offered must be adequate to cater for the increased number of teams as well as the number of fans that will certainly increase.

China is one of the countries that has expressed its interest in hosting the first Mega-World-Cup. China, as seen from the information collected, has a relatively young football culture as well as history (Simons, 2008). It does not match the fat history described by Brazil. Contrarily, China has state of the art facilities, so we can, therefore, attest to its capability of hosting a World Cup event. The country has been able to host many other global events, as it successively hosted the 2008 Olympics in Beijing. The country's football levels have notably improved, which is a result of significant investment by Chinese investors, a strategy that has led to the attraction of global talents.

Massive investments have led to the development of modern training facilities as well as stadiums. The country is, therefore, willing and able to host a huge global sporting event like the World Cup. It should, however, be noted that prior winning a bid to host a FIFA World Cup, the host nation is required to have shown a significant improvement in its football performance ( $\mathrm{Li}, \mathrm{Liu}, \& \mathrm{Wu}, 2010)$. A World Cup is mean to bring 
together competitive teams to compete for a major trophy, not an infant team whose presence in the competition will be insignificant.

\subsection{A Comparison of Past and Future World Cups}

The majority of the World Cup competitions that have been hosted have had many similarities. Most of the host nations arguably have different football culture, as well as different levels of domestic leagues. Regardless of these, there have been significant similarities in terms of the challenges witnessed. In Brazil, for example, officials were apprehended for being involved in fraud. A Swiss FIFA official was arrested and prosecuted for involvement in the sale of hospitality tickets wrongfully and at inflated prices. The objective of most hosts of FIFA World Cup competitions is to provide adequate facilities, as well as quality services to both fans as well as participating nations.

Host nations of the future are required to emulate the successes that have been made by other hosts in the past. Much is required from them, as World Cup hosts of the future are required to stand firm and ensure that past setbacks are not repeated. Significance occurrences have led to the development of new strategies that will ensure that there is no repeat of past mistakes. Match officiating, for example, has improved significantly. England's Frank Lampard had an equalising goal disallowed against Germany in the 2010 World Cup's round of 16. This led to the introduction of goal-line technology, a measure being used in England's Premier League, to ascertain goal validity (Pier, Marco, Massimiliano, \& Stella, 20 January 2015).

\section{Conclusion and Recommendations}

Hosting an international event is a privilege. Countries that do so get to have tremendous improvement of their infrastructures. Generally, social amenities and boarding facilities such as hotels and communication will all be improved to meet international standards. The host nation gets to earn millions in revenue from ticket sales and TV rights. Furthermore, such global events promote a country's tourism, which further increases earning potential. Prestige is attained by the country in which the global event succeeds. Global events have certainly been used to market a country in the recent past (Jesse \& Ronald, 2012). A country's capability to host such a big event with ease states that a country may be a good destination for investors to venture. In the end, a country will generate revenue from profits made by foreign investors.

Much has been achieved to ensure that World Cup tournaments are successful, but this does not mean that some setbacks do not exist. In the World Cup that is due to be held in Russia in 2018, some key issues must be addressed. Russia has a well-developed domestic league. However, there are negativities which some of its fans tend to display (Rafael, 2014). In the recent past, players of African descent have been racially abused. Much still has to be done in the fight against racism in the country. It is understood that the average size of a World Cup soccer stadium should have the capacity of carrying a minimum of 45,000 people. The average stadium attendance of Russia's domestic league is 11,500. The Russian Football Federation is therefore tasked with ensuring that it markets its domestic league so that it can generate much revenue from domestic fans during the upcoming completion due in 2018.

\section{Acknowledgements}

The authors would like to thank the following people for their helpful feedback on this document:

6.1. Te-Yi Chang, Catherine Lee and Ya-Hui Su for their various suggestions and corrections.

\section{References}

[1] Alex, B. (2002). Futebol: the Brazilian way of life. London. Bloomsburg, 37.

[2] Amelia, M. (2010, August 1). Brazil Football. Retrieved from Brazil Football: http://www.brazil.org.za/football.html 
[3] Dave, T. (1994). The Little Red Book Of Chinese Football. Yore Publications.

[4] Edward, D. (2014, July 29). What are the advantages and disadvantages of hosting an international sporting event? Retrieved from Quora: https://www.quora.com/What-are-the-advantages-and-disadvantages-of-hosting-an-international-sporting-event

[5] Grey, R. (June 15th, 2014). Scoring Wilder. R.S. Grey Publishers.

[6] Jaci, B. (February 1st, 2011). The Perfect Play. Penguin Berkley Heat.

[7] Jesse, R., \& Ronald, C. (May 10th 2012). Football in China. Book on Demand Ltd.

[8] Li, C., Liu, X., \& Wu, C. (2010). Chinese Football Insider. Jiangsu People's Publishing LTD.

[9] Lu, J. (2012, February 19). Let professionals run Chinese soccer. Retrieved from South China Morning Post: http://www.scmp.com/article/993090/let-professionals-run-chinese-soccer

[10] M.Davis, L., \& Clark, A. S. (1987). Tourism trends in the Asia Pacific region.

[11] Mehta, R., \& Sivadas, E. (1995). Comparing response rates and response content in mail versus electronic surveys. Journal of the Market Research Society, 37(4), 429-439.

[12] O'Neill, S. (2014, May 29). Brazil World Cup tourism - negative or positive impact? Retrieved from International Tourism Partnership: http://www.greenhotelier.org/destinations/americas/brazil-world-cup-tourism-negative-or-positive-impact/

[13] Pier, L. M., Marco, L., Massimiliano, N., \& Stella, E. (20 January 2015). On-Field Testing and Evaluation of a Goal-Line Technology System. Advances in Computer Vision and Pattern Recognition, 67-90.

[14] Rafael, S. (2014, July 22). Russia 2018: Major challenges for next World Cup hosts. Retrieved from BBC: http://www.bbc.com/news/world-europe-28409784

[15] Richard, E. (2012, July 8). Brazil's Samba style looking so out of step. Retrieved from EXPRESS: http://www.express.co.uk/sport/football/331543/Brazil-s-Samba-style-looking-so-out-of-step

[16] Richard, W. (2014, June 5). Futebol Nation by David Goldblatt review - Richard Williams's World Cup books. Retrieved from The Guardian: https://www.theguardian.com/books/2014/jun/05/richard-williams-football-books-brazil-world-cup-2014

[17] Simon, K., \& Stefan, S. (2009). Soccernomics: Why England Loses, Why Germany and Brazil Win, and Why the U.S., Japan, Australia, Turkey--and Even Iraq--Are Destined to Become the Kings of the World's Most Popular Sport. Nation Books.

[18] Simons, R. (May 1st, 2008). Bamboo Goalposts: One Man's Quest to Teach the People's Republic of China to Love Football. Pan Macmillan.

[19] Tang, S. (April 21st, 2004). Economic Feasibility of Projects: Managerial and Engineering Practice. Chinese University Press.

[20] William, O. (26 Nov 2015). Events Feasibility and Development. London: Taylor \& Francis Ltd.

[21] Yin R K (2009) Case study research: design and methods. 4th ed. London: Sage 